reason that the author has focused his attention chiefly on problems and difficulties. We should be most grateful for such a sincere expression of the thoughts and reactions of so eminent a scientist and administrator.

ROBERT ROBINSON

\section{MODERN PHYSICS WITHOUT TEARS}

\section{Atoms and the Universe}

An Account of Modern Views on the Structure of Matter and the Universe. By Prof. G. O. Jones, Prof. J. Rotblat and G. J. Whitrow. Pp. 254+31 plates. (London: Eyre and Spottiswoode (Publishers), Ltd., 1956.) 25s. net.

TN this book the authors have attempted an overall 1 review of modern discoveries and ideas in physics and astronomy within the space of 250 pages. Though, in doing this, they have, as they say, had "to abandon one of the main characteristics of scientific method-its insistence on rigour in argument and explanation", the result is almost completely successful in giving the reader a convincing sketch-picture of recent achievements.

With my own specialized knowledge of atomic physies, I found the astronomical part of the book of greatest interest. This is extremely concise and closepacked with interesting facts and speculations. It is beautifully illustrated with a number of plates of planets and nebulæ. But it is quite possible to imagine an astronomer who would be more interested in the part of the book dealing with atomic physics.

The only unsatisfactory part of the book is that in which the authors try to explain very briefly the ideas of relativity and quantum mechanics. This was probably an impossible task; but I think that more than two pages might have been devoted to experiments and illustrations of the wave-properties of matter and that the considerations of the levelstructure of atomic and molecular systems might have been amplified, since a great deal of the astronomical section involves knowledge of spectra and the shifting of spectral lines by the Doppler effect (beautifully illustrated, it is true, but nowhere explained).

But it would be surprising if one could not pick holes in such a book. It is very pleasant to see that the authors have found it possible to describe in simple, non-mathematical terms so much of modern physics and astronomy. There must, of course, be a limit to such an attempt. Quantum and general relativity ideas are not only less familiar than classical ideas, they are also more difficult to understand and to deal with. The Uncertainty Principle sets a limit to one's knowledge, especially to the knowledge one can express in familiar terms. Fortunately, much of physics is still 'classical', if we can tack on such fundamentally non-classical, but easily understood, developments as radioactivity. Astronomy is nearly 'classical' if one accepts the Einstein equivalence of mass and energy, and the motions of fundamental particles are mostly 'classical' until we have to deal with interactions, which involve various diffraction effects. Thus there is a large section of modern physics which can be visualized in more or less classical terms, and the authors have rightly exploited this. Indeed, the ordinary physicist should do just this in his experimental work-he should try to think things out for himself as simply as possible, if some. times inaccurately, rather than wait for the pure mathematician to tell him all the answers.

I am sure that many of the simplified discussions in the book will prove of interest even to the professional in physics and astronomy. As a review of modern discoveries in these subjects, the book is excellent for the scientist who does not specialize in them. It certainly should be read by all students of physics or applied mathematics as a supplement to their formal text-books, and it can also be strongly recommended to the layman who has some background knowledge of physics.

H. W. B. SkINNER

\section{CRYSTAL PHYSICS}

Handbuch der Physik

Herausgegeben von S. Flügge. Band 7, Teil 1: Kristallphysik, 1. Pp. vii +687 . (Berlin : SpringerVerlag, 1955.) 122.50 D. marks.

7 HIS book is one of the first parts to appear of the new "Handbuch der Physik" ; together with Part 2 of Vol. 7, it will form a complete work on crystal physics. The necessity for two parts gives some idea of the importance of crystal physics to the other main branches of science. The book contains four sections: crystallography (102 pp., by H. Jagodzinski, in German); theory of the mechanical and thermal properties of crystals (221 pp., by G. Leibfried, in German); the specific heat of crystals (58 pp., by M. Blackman, in English); and the theory of lattice faults ( 283 pp., by A. Seeger, in German). Thei'e are two useful indexes giving the German-English and English-German equivalents of a large selection of technical terms. There is no name index.

Each paper is well documented by reference to works in German and English; relatively, there are few references to work in other languages. It is probable that these references will prove to be the most important part of the book, for in the space available some of the sections are rather cramped. Consider the section by Jagodzinski, for example; in one hundred pages it covers formal crystal symmetry, the relation between symmetry and physical properties, descriptions of some basic structures, and the relation between crystal structure and physical properties. The author has introduced several new ideas into the presentation of spacegroup theory, and I am particularly pleased to see that his treatment does not take the existence of the Bravais space-lattices for' granted. On the other hand, ther'e is a section entitled "Ein Weg zür lückenlosen Ableitung der 230 Raumgruppen" which disposes of the subject in four pages of text.

There is, unfortunately, a small degree of overlapping with the next section, by Leibfried, whose main object, however, is to give a general review of the theory of interatomic forces rather than to describe their effects in particular crystals. It is rather heavily mathematical, descending only occasionally to compare theoretical results with experiment, and omitting completely any descripticns of experimental methods. Experimentalists, however, should find this section useful in showing what type of experimental result is most useful in the general theoretical development of the subject.

Leibfried's and Blackman's sections again overlap appreciably; both discuss the Debye theory in some 